Original Article

\title{
A STUDY ON THE CULTURAL PRACTICES OF POSTNATAL MOTHERS IN SELECTED HOSPITALS AT MANGALORE
}

\author{
Sunanda $B^{1} \&$ Shynee Paul ${ }^{2}$ \\ ${ }^{1}$ Il year M .Sc (N) student, ${ }^{2}$ Professor, Department of Obstetrics \& Gynaecological Nursing, \\ Nitte Usha Institute of Nursing Sciences, Nitte University, Deralakatte, M angalore - 575018 \\ Correspondence: \\ Sunanda B. \\ Nitte Usha Institute of Nursing Sciences, Nitte University, Deralakatte, M angalore - 575018
}

\begin{abstract}
:
Culture may be defined as a shared system of beliefs, values, and behavioural expectations that provide social structure for daily living. Much of the woman's behaviour during the postpartum period is strongly influenced by her cultural background. This study was conducted to identify the cultural practices among the postnatal mothers in selected hospitals at M angalore. The data was collected from 200 samples between 17-09-12 and 03-11-12 in various hospitals at Mangalore. Descriptive survey research approach was adopted, and collected data were analyzed using descriptive and inferential statistics. Distribution of the samples based on demographical characteristics revealed that $49 \%$ of the samples were in the age group of $25-29$ years, $48.5 \%$ of the samples had primary education, $49.5 \%$ of the samples were from Muslim religion, $89 \%$ of the home makers, $65.5 \%$ of the joint family and $76 \%$ of the rural mothers were participated in the study. Majority of the mothers were consumed home medicine, restricted to use cold water, restricted to perform spiritual activities, $16.5 \%$ of the mothers had a practice of applying herbal medicine to hasten the cord to dry during the postnatal period. $59.5 \%$ of the mothers were following unhygienic practice that using a cloth soaked in baby's urine to remove the coated tongue. Hence the study concluded that the postnatal mothers had followed some of the cultural practices mostly in rural areas.
\end{abstract}

Keywords : Cultural practices, postnatal mothers, multiparous.

\section{Introduction :}

Much of the woman's behaviour during the postpartum period is strongly influenced by her cultural background. In today's world, where travel is commonplace, nurses are likely to come in contact with women from many different countries and cultures.

Every society has its own traditional beliefs and practices related to pregnancy and health care. Beliefs in super natural power that is holy rituals, salvation offerings and sacrifices are applied at the different stages of life from birth to death. There are many such practices, rituals,

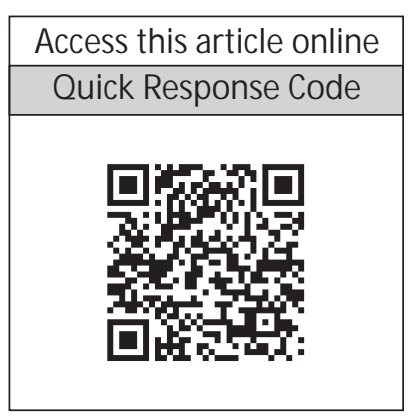
beliefs and offerings which either protect or harm the health of the mother and foetus in utero. Culture influences the way people of a group view themselves, their expectations, and their behaviour in response to certain situations

Providing culturally competent nursing care means that care is planned and implemented in a way that is sensitive to the needs of individuals, families and groups from diverse cultural populations within society. The nurse who recognizes and respects cultural diversity has cultural sensitivity and provides nursing care that accepts the significance of cultural factors in health and illness

Postpartum maternal health care influences the health of both the mothers and their children greatly. Like prenatal care, the postpartum health care that is typically provided during the six-week period after childbirth is very important to the mothers' health. 'In developing countries, over $60 \%$ of maternal deaths occur during the postpartum period. Effective postpartum care is essential to maximize survival of mothers and new born regardless of where a woman delivers

India, being a land of diverse cultures and traditions, 
postpartum care and diet varies, based on topography of the region, culture, tradition and religious practices

Culturally competent care involves knowledge of the various dimensions of care, including moving beyond the biomedical needs of the patient. Rather, a holistic approach is one that expands knowledge. Changes attitudes, and enhances clinical skills. To provide optimal care in a variety of clinical settings, it is important for health care professionals to conduct cultural assessments and expand their knowledge and understanding of culturally influenced beliefs, common health care practices, customs, and rituals.

In conclusion, researcher need to recognize that cultures reflect life experiences; they should be sensitive to cultural differences in postpartum beliefs and practices as the first step toward developing their cultural competence. With these references, the investigator has taken up a study related to cultural practices hence exploring it in the society.

\section{Materials and methods}

Research approach: Descriptive survey research approach.

Research design: Descriptive designs are designed to gain more information about characteristics within a particular field of study.

Setting: The study was conducted in various hospitals at Mangalore.

Population: The population selected for the study comprises of multiparous postnatal mothers in selected Hospitals at M angalore.

Sample/Sampling techniques: The purposive sampling technique was adopted to select 200 postnatal mothers.

Instrument/ Method of data collection: The tool was used to collect the data 1) Demographic Proforma consists of 7 items which includes age, education, religion, occupation, income, the type of family, and area of residence and 2) structured questionnaire of cultural practices consists of 40 items divided into five sections like Diet, Bath, Spiritual activity, Breast feeding and Baby care.
Analysis: The data was analysed using SPSS version 16.0. Results were tabulated and depicted graphically.

Statistical Analysis: Frequency distribution and percentage wasused for analysis of the result.

\section{Results:}

Analysis of base line characteristic of subjects revealed that among multiparous postnatal mothers $49 \%$ belongs to the age group of $25-29$ years, $48.5 \%$ of the mothers were having Primary education, $49.5 \%$ of the mothers were belongs to Muslim religion, $89 \%$ of the participants were homemakers, $65.5 \%$ of the mothers belongs to Joint family and $76 \%$ of the participants were from rural area.

TABLE 1; DISTRIBUTION OF SAM PLES ACCORDING TO DEM OGRAPHICCHARACTERISTICS

$\mathrm{N}=\mathbf{2 0 0}$

\begin{tabular}{|l|c|c|}
\hline DEM OGRAPHICVARIABLES & FREQUENCY & PERCENTAGE(\%) \\
\hline AGE & 29 & 14.5 \\
$20-24$ & 98 & 49.0 \\
$25-29$ & 61 & 30.5 \\
$30-34$ & 12 & 6.0 \\
$35-39$ & & \\
\hline EDUCATION & 8 & 4.0 \\
No formal education & 97 & 48.5 \\
Primary & 56 & 28.0 \\
Secondary & 28 & 14.0 \\
PUC & 11 & 5.5 \\
Degree \& above & & \\
\hline RELGION & 28 & 14.0 \\
Hindu & 99 & 49.5 \\
Christian & 73 & 36.5 \\
Muslim & & \\
\hline OCCUPATION & 178 & 89.0 \\
Home maker & 22 & 11.0 \\
Private employee & & \\
\hline INCOME IN RUPEES & 24 & 12.0 \\
3001-5000 & 68 & 34.0 \\
5001-7000 & 87 & 43.5 \\
7001-10000 & 28 & 14.0 \\
\hline >10000 & & \\
\hline TYPE OF FAMILY & 69 & 34.5 \\
Nuclear & 131 & 65.5 \\
Joint & 152 & 76.0 \\
\hline AREA OF RESIDENCE & 48 & 24.0 \\
Rural & & \\
Urban & & \\
\hline
\end{tabular}

The item wise distribution of sample according to the cultural practices (diet, bath, spiritual activity, breast feed and baby care) described under different headings. 
DIET: The present study shows that, in dietary practices during postnatal period, only few $(28 \%)$ of the postnatal mothers consumed green leafy vegetables to prevent cold to mother and the baby too. $80.50 \%$ of the mothers had practice of drinking kalijira kashayam and $79.5 \%$ of the mothers consumed special food (home medicine) to increase breast milk and strengthen the bones and muscles during postnatal period. This food is highly nutritious, contains more of ghee, methi and garlic, which helps to increase the breast milk.

BATH: During the post partum period $52.5 \%$ of the mothers were restricted to oil massage before hot water bath for 40 days and $56 \%$ of the postnatal mothers were restricted from using cold water for washing hands, taking bath, toilet use and drinking purpose.

SPIRITUAL ACTIVITIES: Majority (84.5\%) of the postnatal mothers were restricted to spiritual activities and $87.5 \%$ mothers had performed purification ceremony. However, the $65 \%$ of people were practicing to keep metal and broom stickunder the bed.

BABY CARE: In order to prevent/reduce the cold to the baby, $64 \%$ of the postnatal mothers were including the herbs in baby bath. $16.5 \%$ of the postnatal mothers have applied the herbal medicine to the cord. However $62 \%$ of the postnatal mothers had practiced to dispose the dried cord by burial method. The investigator found that the practice of disposal of dried cord by postnatal mothers in Muslim religion, by 14th day with few hairs of the baby, along with a coin will be kept on the coconut tree or put into the stream of water. The very beginning of the postpartum days the breast milk production will be insufficient. In order to improve the bowel movement of the baby, the postnatal mothers were practicing to give hot water to the baby. The present study showed that $20 \%$ of the mothers had practiced to give hot water to the baby. $38 \%$ of the mothers had practiced to give home medicine (includes garlic, ginger, pepper and shoot of some selected plants) to the baby to relieve the abdominal discomfort. Application of kajal and use of black thread practice was $99 \%$ of the mothers had followed after the naming/purification ceremony to prevent bad eyes. Even though the urine is a source of infection to the baby, $59.5 \%$ of the mothers were following unhygienic practice that using a cloth soaked in baby's urine to remove the coated tongue. Although the smoke is not good for health, the $79 \%$ of the mothers were had practice of exposing the baby to the dhoopam smoke after bath to protect the baby from evil spirit.

\section{Comparison of cultural practices of postnatal mothers with selected demographic variables.}

Age: The major findings identified during the Comparison of the cultural practices with age showed that, $100 \%$ of the postnatal mothers with all age groups had a practice of consumption of warm food after delivery whereas $95 \%$ of the postnatal mothers of the age group of 30-34 years practiced to drink kalijira (black cumin seed) kashayam for first 3 days after delivery. About $58 \%$ of the postnatal mothers of age group of 35-39 years were restricted to drink more water. $89 \%$ of the postnatal mothers with age group of 30-34 years had a practice of consuming special food (home prepared) to increase the lactation and strengthen the bones and muscles.

Comparing the cultural practices regarding spiritual activity with different age group revealed that, $96 \%$ of the postnatal mothers (20-24 years) were restricted to perform spiritual activities before 40 days, $70 \%$ of the postnatal mothers (30-34 years) had a practice of keeping metal and broom stick under the bed. Thirty three percent of the mothers (35-39 years) applied some home medicine to the cord to dry faster, $67 \%$ of the postnatal mothers (35-39 years) disposed the cord by burial method. Hundred percent of the postnatal mothers with all the age group practiced the application of Kajal on the baby's face and use of black thread to prevent bad eye after the purification ceremony. $100 \%$ of the mothers with an age group $25-29$ years practiced to remove coated tongue by using a cloth soaked in baby's urine.

Education : During the comparison of the cultural practices of postnatal mothers with the education, the researcher found that, $100 \%$ of the mothers with all the categories of 
education practiced to consume warm food, $99 \%$ of the mothers with primary education drank Kalijira (black cumin-seed) for first 3 days. $84 \%$ of the mothers with secondary education consumed special food (home preparation) to increase the lactation and strengthen the bones and muscles.

Hundred percent of the postnatal mothers with no formal education were restricted to perform spiritual activities before 40 days, $71 \%$ of the mothers with PUC practiced to keep the metal and broom stickunder the bed.

Hundred percent of the mothers with educational qualification of degree $\&$ above fed the (colostrums) first milk, $74 \%$ of the mothers with primary education buried the cord when it dries and falls. With all the categories of education mothers practiced to apply Kajal on the baby's face and also of tying black thread to prevent bad eye after the purification ceremony. The majority (88\%) of mothers with no formal education practiced to remove coated tongue by using a cloth soaked in baby's urine.

Religion: There were significant differences observed in comparison of the cultural practices with the religion that, $100 \%$ of the mothers practiced the consumption of warm food after delivery. Majority (97\%) of the Hindu postnatal mothers practiced to drink Kalijira kashayam (black cuminseed) for first 3 days. $58 \%$ of the Hindus were restricted to drink more water. $92 \%$ of the Hindus were consumed special food (home preparation) to increase the lactation and strengthen bones and muscles.

Ninety eight percentages of the M uslim postnatal mothers were restricted to perform spiritual activities before 40 days. Majority (95\%) of the Hindu mothers practiced to keep the metal and broom stick under the bed. $18 \%$ of the M uslim mothers were applied home medicine and herbal oil to the cord to dry faster. All the religion mothers (100\%) were practicing to apply Kajal on the baby's face to prevent bad eye after the purification. $67 \%$ of the M uslim mothers were practicing to remove coated tongue by using a cloth soaked in baby's urine.

Occupation: The result of comparison of the cultural practices during postnatal period with the occupation showed that, $100 \%$ of the mothers practiced to consume warm food. The majority (96\%) of the home makers were drinking Kalijira (black cumin-seed) for first 3 days, 47\% were restricted to drink more water, $81 \%$ were consuming special food (home medicine) to increase lactation and to strengthen the bones and muscles, $91 \%$ were restricted to perform spiritual activities, $66 \%$ were keeping metal and broom stick under the bed to prevent evil spirit and $66 \%$ have buried the cord when it dries and falls during the postnatal period.

Hundred percent of the private employees applied Kajal on the baby's face and tied black thread around the waist to prevent bad eye. $64 \%$ of the home makers removed coated tongue by using a cloth soaked in baby's urine.

Family: The findings of the cultural practices compared with different types of families showed that, the majority (95\%) of the mothers from joint family were drinking Kalijira (black cumin-seed) for first 3 days. $47 \%$ of the mothers from the joint family were restricted to drink more water. $84 \%$ of the mothers from nuclear family practiced to consume special food (home preparation) to increase lactation and to strengthen the bones and muscles.

Ninety one percent of the mothers from joint family were restricted to perform spiritual activities. M ajority (93\%) of the mothers from nuclear family were practiced to keep metal and broom stick under the bed, $64 \%$ of the mothers from the nuclear family have applied home medicine to the cord dry faster. $66 \%$ of the mothers from joint family had a practice of burial the cord. The majority (99\%) of the mothers from nuclear family were practicing to expose the baby to the dhoopam smoke after the bath.

The $100 \%$ of the mothers from nuclear family practiced to apply Kajal on the baby's face and tied black thread to prevent bad eye and also practiced to remove the coated tongue by using a cloth soaked in baby'surine.

Area of residence : The comparison of cultural practices with area of residence showed that, $100 \%$ of rural and urban postnatal mothers were practicing the consumption 
of warm food after delivery. Majority (95\%) of the rural mothers were practicing to drink Kalijira (black cuminseed) for first 3 days, $46 \%$ of the rural mothers were restricted to drink more water. M ajority (87\%) of the urban mothers consumed special food (home preparation) for increased lactation and to strengthen the bones and muscles.

The $73 \%$ of the urban mothers practiced oil massage before bath during postnatal period. The majority (96\%) of the rural mothers were restricted to perform spiritual activities, $66 \%$ were practiced to keep metal and broom stick under the bed, $15 \%$ were applied home medicine to the cord to dry faster and $68 \%$ were buried the cord when it dries and falls. The $100 \%$ of the urban mothers applied Kajal and tied black thread to the baby for prevention of bad eye. The majority (68\%) of the rural mothers practiced to remove the coated tongue by using a cloth soaked in baby'surine.

\section{Discussion :}

To achieve the objectives of the study a descriptive survey approach was considered. Non-probability purposive sampling technique was used to select the samples. The data was collected from 200 postnatal multiparous women in selected hospitals at $M$ angalore.

The findings of the study were discussed under following sections;

Section-A: classification of demographic variables

Section-B: assessment of cultural practices of postnatal mothers.

Section-C: comparison of cultural practices with the demographical variables.

\section{Section-1: classification of demographic variables is as follows;}

I Analysis of base line characteristic of subjects revealed that the $49 \%$ of postnatal mothers were belongs to the age group of 25-29 years.

I M ajority (48.5\%) of the mothers were having Primary education.

I M ost (49.5\%) of the mothers were belongs to M uslim religion.
I Referring to the occupation the majority (89\%) of the participants were home makers.

I The highest percentage (43.5\%) of the mothers had monthly income of Rs. 7001-10000.

I Majority (65.5\%) of the mothers were from Joint family.

I Majority (76.0\%) of the participants were from rural area.

\section{Section - B: assessment of cultural practices of postnatal} mothers.

I All the (100\%) postnatal women were consuming hot food after delivery.

I Majority (79.5\%) of the mothers consumed special food (home preparation) to increase lactation and to strengthen the bones and muscles.

I Most of the postnatal mothers (98.5\%) were restricted to regular hot water bath up to 40 days.

I Majority (87.5\%) of the mothers have followed the purification ceremony.

I Majority (99\%) of the mothers applied the kajal and black thread to the baby after the purification ceremony to prevent bad eye.

Section-C: comparison of cultural practices with the demographical variables;

I Comparing the cultural practices with the age revealed that the highest percentage of practices were followed by the age group of 35-39 years

I The researcher found that during the comparison with the educational status, the mothers with no formal education and degree $\&$ above had followed highest percentage of cultural practices during postnatal period.

I The mothers from Hindu religion followed highest percentage of cultural practices in postnatal period.

I The home makers were giving more importance to the cultural practices of postnatal mother.

I The highest percentage of the mothers from nuclear family were followed the cultural practices.

I Majority of the rural postnatal mothers were following the cultural practices 


\section{Conclusion :}

Generally, women and their newborn are secluded from the rest of the household to limit contamination from the polluting powers of 'after-birth'. This is widely practiced across India, and is an intrinsic part of women's daily lives in traditional societies. Health professionals should be aware of the patient's culture and which traditional belief

\section{References}

1. Taylor Carol, Lillis. Fundamentals of Nursing. $1^{\text {st }}$ edition. New Delhi: Elsevier; 2004.

2. Joanna H Raven. Traditional beliefs and practices in the postpartum period in Fujian Province, China: j.raven@liverpool.ac.uk. Available from; http:// www.biomedcentral.com/1471-2393/7/8

3. BioMed Central, BMC Public Health Research article Open Access Postpartum practices of puerperal women and their influencing factors in three regions of Hubei,China. Availablefrom:http:// www. ncbi.nlm.nih.gov/pmc/articles/PM C1636040/

4. Belief and Practices of Traditional Post Partum Care Among a Rural Community in Penang Malaysia. Available from: http:// ww w.ispub. com/journal/the-internet-journal-of-third-world-medicine/ volume9

5. postpartum,carelndianstyle.Availablefrom:http://yourkidandyou. blogspot.in/2012/02/postpartum-care-indian-style.html

6. Perry and Potter. Basic Nursing. $2^{\text {nd }}$ edition. Jaypee Brothers, Medical Publications (P) LTD New Delhi. 2008.

7. Ward L Susan, Hisley M Shelton. Maternal Child Nursing Care. New Delhi: Jaypee Brothers, Medical Publications (P) LTD; First edition.2010.

8. Lowdermilk, Perry. Maternity And Women's Health Care. Eighth Edition. M issouri: Mosby; 2004.

9. The American Journal of Maternal/Child Nursing $2003 \mathrm{March} / \mathrm{April}$, Volume 28 Number 2: Pages 74 - 78. Available from: http://www. google.co.in

10. Lala VR, Desai AB. Feeding of newborns and infants (cultural aspects). PMID:12265032 [PubM ed - indexed for M edline] 1970; Jul 5(3):191-7. Available from; http:// www.ncbi.nlm.nih.gov/pubmed/12265032 complements professional care. Healthcare providers should also advice and educate women about and importance of adhering to the standard practice of postpartum care while outlining appropriate strategies for integration of mother's traditional beliefs and modern approaches of postpartum care. 